\title{
Education and research in the field of renewable sources of energy in the Centre Of Sustainable Development And Energy Savings WGGIOS AGH in Miekinia
}

\author{
Wojciech Górecki ${ }^{1}$, Jarosław Kotyza ${ }^{1}$,Elżbieta Hałaj $^{1 *}$, ${\text { Wojciech } \text { Luboń }^{1} \text {, Grzegorz Pełka }}^{1}$, \\ Anna Sowiżdżal ${ }^{1}$, Dominika Dawiec ${ }^{1}$, Paulina Smaczna ${ }^{1}$, and Daniel Malik ${ }^{1}$ \\ ${ }^{1}$ AGH University of Science and Technology, Faculty of Geology, Geophysics and Environmental \\ Protection, A. Mickiewicza 30 Ave, 30-059 Krakow, Poland
}

\begin{abstract}
The Centre of Sustainable Development and Energy Savings of the Faculty of Geology, Geophysics and Environmental Protection of AGH University of Science and Technology in Miekinia conducts research and educational activities in the field of renewable sources of energy, geothermal heat pumps especially. Growing interest in using the renewable energy sources (RES) is reflected upon the interest in such a discipline of studies. Many people declare intention of studying RES. This is a modern discipline, opened at AGH University of Science and Technology in 2003 as the first in Poland. Since 2012, when the Centre was open ca. 8000 people (including students, pupils, local governments and communities) were educated here. Not only geothermal energy is a main focus attention field. In the Centre other renewable sources of energy are also researched. This include solar energy (both photovoltaic and thermal), solid fuel boilers and wind energy.

The Centre is heated by heat pumps with ground sources which are simultaneously use by students for practice and measurements. There are didactic heat pumps with temperature and pressure sensors and electric meters to be used by students during measurements. The Centre is in disposal of self-constructed Thermal Response Test device for thermal parameters measurements. In a stand for testing ground-source brine heat pumps for central heating and hot domestic water preparation research are conducted on the COP heat pump efficiency in accordance with the PN-EN 14511 standard. The Centre works on the prototyping of new, innovative heat pumps.
\end{abstract}

\section{Introduction}

The Centre of Sustainable Development and Energy Savings of the Faculty of Geology, Geophysics and Environmental Protection of AGH University of Science and Technology

*Corresponding author: elzbieta.halaj@gmail.com 
in Miekinia conducts research and educational activities in the field of renewable sources of energy (RES). The Centre promotes development of all kind of RES, but the most emphasised are geothermal heat pumps. The Centre is placed in the former mine administrative building which was fully modernized for educational and laboratory purposes and energy efficiency improvement of the building was done there (Fig. 1). Construction of the Laboratory was co-financed by the European Regional Development Fund of the European Union under the Malopolska Regional Operational Program 2007 2013.

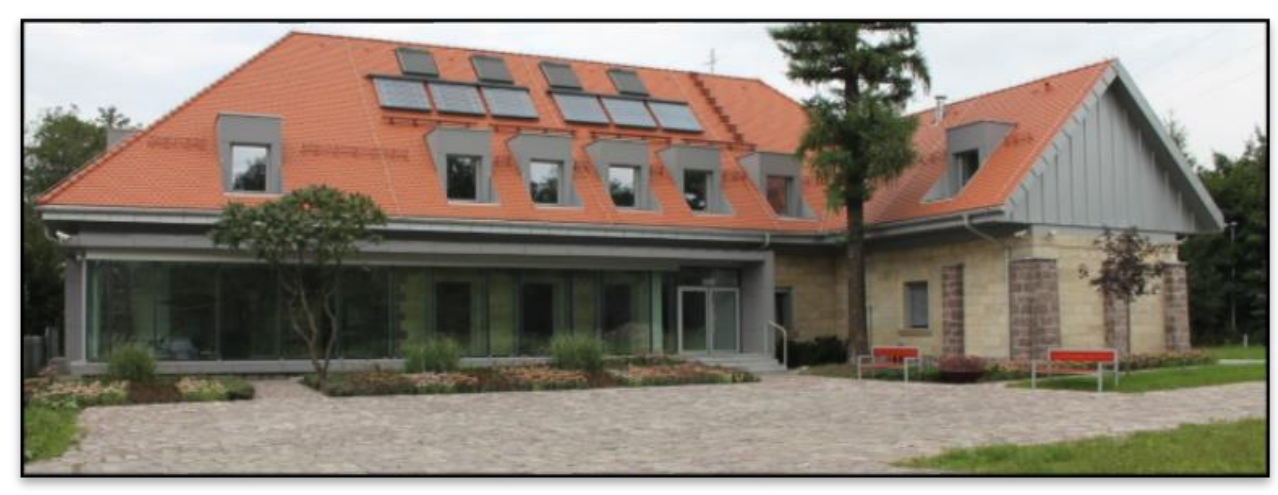

Fig. 1. The main building of the Centre in Miekinia.

\section{Education}

Growing interest in using the renewable energy sources (RES) is reflected upon the interest in such a discipline of studies. Many people declare intention of studying RES. This is a modern discipline, opened at AGH University of Science and Technology in 2003 as the first in Poland. Modern and RES dedicated infrastructure in the Centre created possibilities for practical courses and laboratory studies which enrich the University educational offer and improve the quality of teaching [1].

Heating system of the Centre is not only utilized for heating purposes but also for demonstration. Students can work on operating heating system, which allows them to be familiar with heat pumps and biomass boilers during operation and observing of any stage of the system functioning. The primary heat source for the building is expanded research station based on 4 ground heat pumps, which supply heat to the building. These devices operate at different temperatures of heat sinks. Three of them have borehole heat exchangers as a heat source, and one has a horizontal ground heat exchanger. At the two laboratory stands there is a possibility to test the impact of passive cooling on the efficiency of heat pump. There is also possible to reconfigure the system to support the regeneration of ground source using solar collectors. Parameters of heating installation can be monitor via BMS (Building Management System). Apart from that in the Centre there are didactic heat pumps dedicated for students practice (Fig.2). 


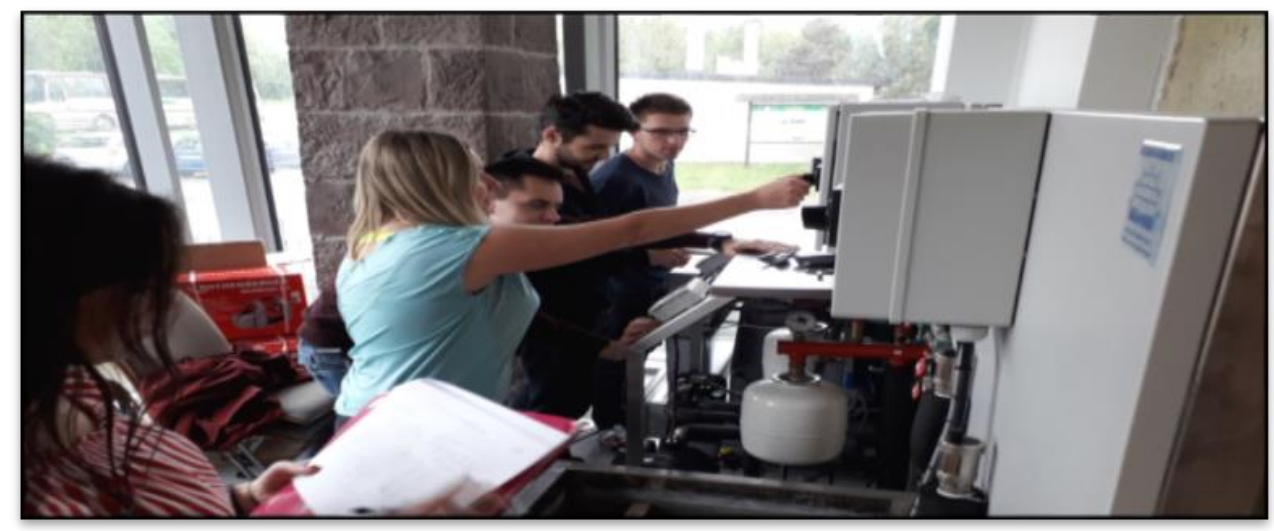

Fig. 2. Heat pump efficiency tests during academic internships

Not only geothermal energy is a main focus attention field. In the Centre other renewable sources of energy are also researched. This include solar energy (both photovoltaic and thermal), solid fuel boilers and wind energy [2].

The Centre served not only students. Since 2012, when the Centre was open ca. 8000 people were educated here. This includes students, pupils, local governments, local communities and energy consultants. More and more local communities are interested in RES field and growing interest in education and demonstration of RES is observed.

These Centre is also mobile. Mobile laboratories (Fig. 3) are able to go everywhere to promote and teach about renewable energy sources (RES) and reduction of smog. Dozens of locations benefited from mobile education on place. In the mobile laboratory there are several installations that can demonstrate operating principles of renewable energy sources (i. e. solar collectors, photovoltaic, ground or air heat pumps, etc.). In the other one mobile laboratory 3 types of heat sources are usually shown: first, very non-ecological (an old boiler) in which anything can be burn and which can be a source of low emission, second, solid fuel boiler of $5^{\text {th }}$ class (eco design), which can reduce slightly the low emission from a house, and third, a heat pump which cause any emission in place of use. 


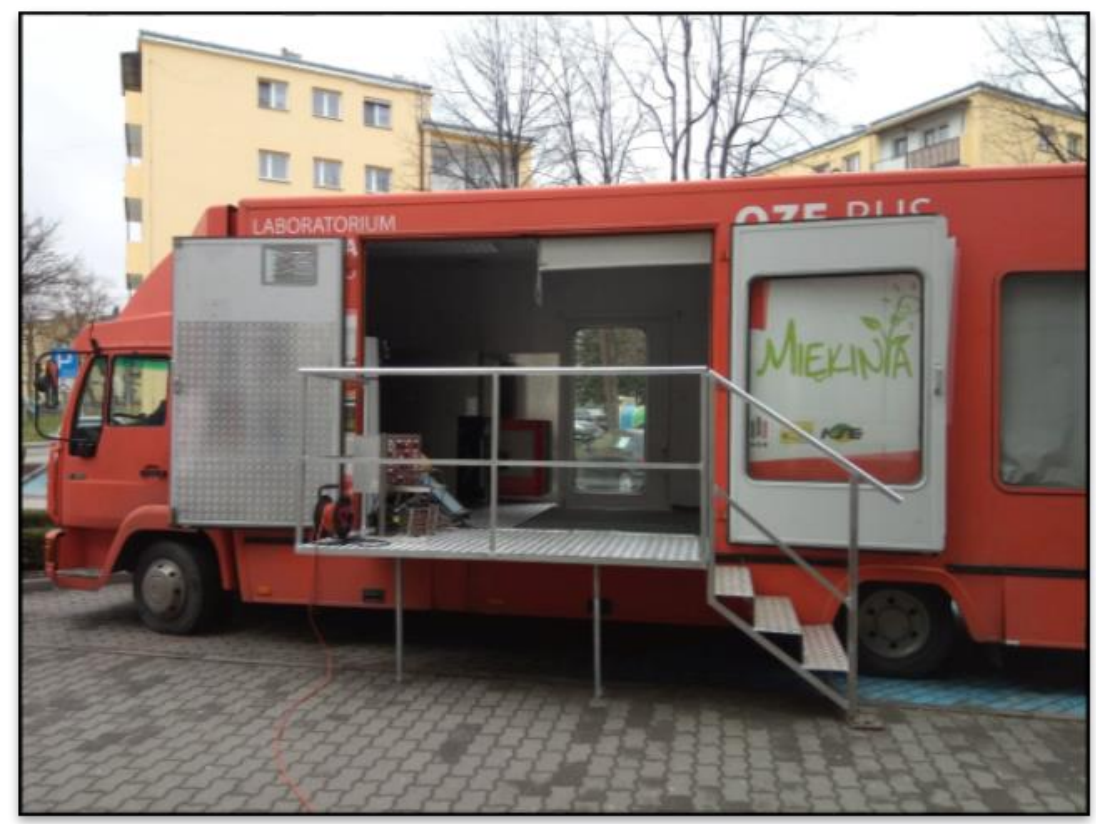

Fig. 3. Mobile RES laboratory (“OZE BUS") ready to be visited

\section{Research}

In the Centre research in the field of geothermal and air heat pumps are carried out. In the Centre of Sustainable Development and Energy Savings of the Faculty of Geology, Geophysics and Environmental Protection of AGH University of Science and Technology in Miekinia, Poland research on efficiency of compressor heat pumps was launched. Within national fund, a stand for testing ground-source brine heat pumps for central heating and hot domestic water preparation was built. In the stand research are conducted on the COP heat pump efficiency in accordance with the PN-EN 14511 standard (Fig. 4). Within the research it is possible to determine the heat pump's operating parameters, such as heating power, electrical power and cooling power. The stand also allows testing the parameters of the cooling system of the tested heat pump. 


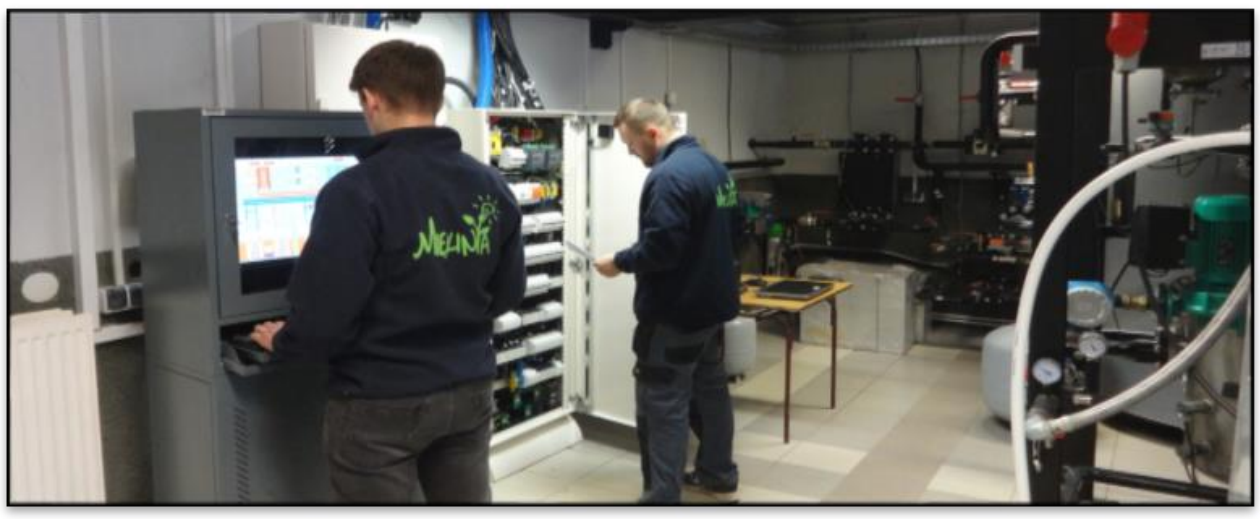

Fig. 4. Heat pump efficiency testing stand

The staff of the Centre works on prototyping of new, innovative heat pumps. This includes heat pumps of the scroll compressor with liquid refrigerant injection. Research works carried out in the Centre regarded also to thermal parameters of the soil using a Thermal Response Test device. The device was self-made by the team of the employees of the Centre.

The Centre cooperates also with several companies from RES industry (i.e. heat pumps and solid fuel boilers producers and installers). Moreover, ca. 100 different SMEs benefited from energy efficiency consultations during SPIN - Malopolska Knowledge Transfer Centres project in 2016-2018 financed from European Regional Development Fund.

\section{Conclusions}

The Centre of Sustainable Development and Energy Savings of the Faculty of Geology, Geophysics and Environmental Protection of AGH University of Science and Technology in Miekinia conducts research and educational activities in the field of renewable sources of energy (RES). The interest of the society in the field of RES is very high and seems not to decline. Meets those expectations the Centre provides renewable sources of energy education and research program for a wide variety of stakeholders [3].

So far, the education and research program targets the most academia. In the future more groups than now will be targeted by special programs and projects. The greater attention would be paid to small business and entrepreneurs. In the near future the Centre will be also an accredited laboratory for heat pumps technology, which opens new horizons for the Miekinia Centre.

\section{References}

1. W. Górecki, J. Kotyza, E. Hałaj, D. Woś, M. Szczygieł, G. Pełka, W. Luboń, International Conference Renewable Energy Sources: engineering, technology, innovations: May 17-20, 2016, Krynica, Poland: book of abstracts 
2. W. Górecki, E. Hałaj, J. Kotyza, A. Sowiżdżał, W. Luboń, G. Pełka, D. Woś, M. Kaczmarczyk, M. Hajto, M. Kaczmarczyk, P. Lachman, Effective use of renewable energy sources : monograph (SOLGEN Sp. z o.o., 2015)

3. E. Hałaj, M. Capik, J. Kotyza , W. Luboń, G. Pełka, D Woś, M. Szczygieł, M. Hajto, Oil and gas power engineering 2015, International Scientific-technical Conference Ivano-Frankivsk April 21-24, 2015 